\title{
The effect of clinical lameness on liveweight in a seasonally calving, pasture-fed dairy herd
}

\author{
J. I. Alawneh, ${ }^{\star 1}$ M. A. Stevenson, ${ }^{*}$ N. B. Williamson, $\dagger$ N. Lopez-Villalobos, $\nmid$ and T. Otleył \\ *EpiCentre, Institute of Veterinary, Animal and Biomedical Sciences, Massey University, New Zealand 4442 \\ †Institute of Veterinary, Animal and Biomedical Sciences, Massey University, New Zealand 4442 \\ $\ddagger$ Tru-Test New Zealand, PO Box 51078, Pakuranga, New Zealand 4442
}

\section{ABSTRACT}

This study investigated the effect of lameness on liveweight (LW) in pasture-fed dairy cattle. The data comprised 222,446 averaged daily LW measurements from 828 lactations of 542 mixed-age cows in a seasonally calving, pasture-fed New Zealand dairy herd. The LW measurements for individual cows were aggregated into weekly averages and analyses conducted to evaluate the effect of a diagnosis of lameness on LW change after controlling for the effect of week in milk, parity, LW at calving, breed, calendar month, and season. In lame cows, LW decreased for up to 3 wk before lameness was diagnosed and for up to 4 wk after treatment. Total LW loss arising from a single lameness episode was, on average, $61 \mathrm{~kg}$ (95\% confidence interval: 47 to 74 $\mathrm{kg}$ ). The results from this study demonstrate how LW records for individual animals can be used to enhance a herd manager's ability to detect lame cows and present them for treatment. The methods presented here show how daily LW monitoring might be used as a tool for early detection of lameness in dairy cattle.

Key words: liveweight, lameness, linear mixed model, animal welfare

\section{INTRODUCTION}

In dairy cattle, DMI is influenced by the ability of an animal to harvest and consume feed and by factors influencing the metabolism of nutrients that are consumed and absorbed (Holmes et al., 2002; Bach et al., 2007). When energy requirements are high and an animal's ability to harvest feeds is compromised, body fat reserves are mobilized so that nutrients can be used for the maintenance of physiological homeostasis as well as the synthesis of milk (Bach et al., 2007; Roche et al., 2009). Lameness, the presence of painful lesions of the foot (hoof and wall) and leg that result in impaired

Received May 2, 2011.

Accepted October 24, 2011.

${ }^{1}$ Corresponding author: j.alawneh@uq.edu.au mobility, compromises an animal's ability to harvest feed. This has important negative effects on production and involuntary culling rates (Green et al., 2002; Onyiro et al., 2008). Lameness can cause significant pain and suffering in affected animals (Whay, 2002), which means that as well as having important economic consequences on herd profitability it also represents an important animal welfare issue. The seriously impaired mobility that arises from lameness conditions and the response to successful treatment reflect the amount of pain and distress that lameness causes in affected animals (Laven et al., 2008).

Given the negative effect of lameness on herd profitability and animal welfare, it is important that those involved in managing dairy cattle are able to identify affected animals as quickly as possible. Identification of affected animals sooner, rather than later, means that appropriate therapeutic interventions can be initiated early. This, in turn, reduces the likelihood that acute conditions of the foot progress to become chronic. A secondary benefit is that recovery times are likely to be shorter, which means that animals are more quickly able to return to a productive state. Given that the economic drivers of milk production in New Zealand have resulted in an increase in the national median herd size and a decrease in the number of labor units per cow (Anonymous, 2010), it is likely that there has been, and will continue to be, a decrease in the ability of individual herd managers to monitor stock intensively to detect lameness events early. Further, with increasing levels of automation on dairy farms, the necessity for those working with dairy cattle to have high levels of animal husbandry skills will decrease (Frost et al., 1997), which is likely to have a negative effect on how promptly lame cows are detected and presented for treatment. Given these trends, it is important that additional methods for identifying lame cows be investigated. Detection of decreases in daily milk yield presents one opportunity for early detection of lame cows (Green et al., 2002). An alternative is detection of liveweight (LW) change using walkover scales positioned at either the entry or exit to a milking parlor. Walkover scales allow the LW 
of individual animals to be recorded at least twice daily. Ongoing, real-time analysis of LW records should allow animals with acute and severe decreases in LW to be identified, signaling to a herd manager that these animals should be carefully examined. An advantage with this approach is that analysis of LW records has been shown to be of use for monitoring both nutrient and reproductive management of herds (Maltz et al., 1997).

Gröhn et al. (1999) used a repeated-measures generalized linear mixed model to determine the effect of ketosis on milk production in 2,604 Holstein-Friesian dairy cows in 8 herds in New York States. This approach allowed short-term average weight change before and after the date of diagnosis to be quantified. The objectives of the current study were to use an approach similar to that of Gröhn et al. (1999) to determine the effect of observed lameness events on LW change and to estimate the total LW loss associated with these events. By doing so we hope to provide a more quantitative estimate of lameness on animal welfare, and to show how daily LW monitoring might be used as a tool for early detection of lameness.

\section{MATERIALS AND METHODS}

\section{Study Animals}

This was an observational study of 828 lactations in 542 mixed-age and mixed-breed (Holstein-Friesian, Jersey, and Holstein-Friesian $\times$ Jersey crossbreeds) dairy cows that calved during the 2008 and 2009 seasons in a university-owned, seasonally calving dairy herd in Palmerston North in the lower North Island of New Zealand (longitude $175^{\circ}$, latitude $-40^{\circ}$ ). Cows grazed as a single group at pasture and had free access to water. The herd was managed so that the pasture allowance and access to supplementation after the morning milking (palm kernel meal to a maximum of $2 \mathrm{~kg}$ of DM/ cow per day and maize silage to a maximum of $2 \mathrm{~kg}$ of $\mathrm{DM} /$ cow per day) was sufficient for maintenance and production requirements of a 400-kg cow producing $2.0 \mathrm{~kg}$ of milksolids/day. Cows were milked twice daily at 0530 and $1500 \mathrm{~h}$ through a 50-bale rotary-platform milking parlor (DeLaval Parallel Rotary, DeLaval International, Tumba, Sweden). The herd used in the present study, as well as a description of the dairy farm where all data were recorded, is described in detail by Alawneh et al. (2011).

Cows were identified using a radio frequency electronic identification system that consisted of lowfrequency $(134.2 \mathrm{kHz})$, high-performance, nonreusable half-duplex ear tags (transponders complied with ISO 11784 and ISO 11785 standards) fitted to each cow and an antenna (Allflex New Zealand Limited, Palmerston
North, New Zealand). Walkover LW were recorded for each cow from the time it joined the milking herd after calving. Liveweight measurements for each cow were measured using an automatic walkover weighing system consisting of the electronic identification system and a calibrated electronic walkover scale system (WoW XR3000, Tru-Test, Auckland, New Zealand).

Clinical lameness cases were identified and managed according to normal farm practice. At the start of the study, the farm manager received detailed instructions from the herd veterinarian to clarify issues around detection of lameness and preliminary treatment of identified cases. The farm manager then trained all staff members to ensure consistent identification and management of lame cows. The following protocol was applied: any cow that was observed by the farm staff as having a persistent gait abnormality was drafted for further investigation. If the diagnosis was footrot, cows identified as lame on examination were then treated by farm staff, otherwise they were held for veterinary examination. All diagnoses other than footrot were made by the first author. After treatment, which was antibiotics for cows with footrot, and trimming for cows with claw horn lesions (with analgesics or antibiotic treatment, if necessary), lame cows were placed on a once-daily milking regimen and kept separate from the main herd in paddocks near to the milking parlor, until the farm staff considered that they had recovered, at which time they were returned to the main milking herd.

\section{Data Management}

Throughout the 2008 and 2009 milking seasons, LW data were downloaded from the scale indicator to a portable personal computer twice weekly. Downloaded data included each cow's electronic identifier, the date and time of each weigh event, and the LW record $(\mathrm{kg})$ as recorded by the scales. Data were transferred to a dairy herd management software package (DairyWIN v99.91.148; Massey University, Palmerston North, New Zealand) allowing LW data to be matched with each cow's biographical and lactation event details [e.g., calving date, insemination date(s), herd test details, and treatment dates and details].

A series of data cleaning procedures was carried out before analysis. A lameness event identified within $14 \mathrm{~d}$ of a prior lameness diagnosis was considered to be the same event unless it occurred in another foot (Dohoo et al., 1983). The $2 \mathrm{LW}$ records for each cow for each day were averaged to provide a single daily measurement. If one record was missing, the remaining record was used as the LW for that day (Alawneh et al., 2011). In the remainder of this paper, we use the term "daily 
LW measurement" to refer to the average daily LW record. The daily LW measurements were then averaged to produce a single weekly LW measurement for each week in milk for each cow. The main reason behind this was to minimize any possible variation in LW measurement that could arise from differences in gut fill, herd management, and milk volume.

\section{Statistical Analyses}

The data set comprised 31,778 weekly LW records (occurring in 222,446 d in milk) and was arranged so that each weekly LW record was regarded as a single observation. Each observation included details of the cow's identity and the following: (1) weekly LW measurement; (2) parity; (3) breed; (4) LW at calving (individual cow LW at calving was quantified by averaging daily LW measurements during the first $7 \mathrm{~d}$ after the date of parturition); (5) weekly LW relative to LW at calving (weekly LW minus LW at calving); (6) presence or absence of a lameness event; (7) production season as a categorical variable (2008 and 2009); and (8) calendar month (period) as a categorical variable with 3 levels (June to September, October to December, and January to May).

The incidence risk of lameness was defined as the total number of cows experiencing at least one lameness event from $50 \mathrm{~d}$ after calving to the end of lactation, divided by the average number of cows present in the herd throughout the same period (Szklo and Nieto, 2007). The incidence rate of lameness was defined as the total number of lameness diagnoses made from 50 $\mathrm{d}$ postcalving to the end of lactation divided by the total number of cow-days at risk. Cow-days at risk for each member of the herd comprised the number of days from d 50 in milk to the date of dry off. For cows that died or were culled, days at risk was the number of days from $\mathrm{d} 50$ in milk to the date of culling or death. Cows that were identified as lame stopped contributing days at risk from the date the lameness event was diagnosed until $14 \mathrm{~d}$ after the last recorded treatment date. After that time, they became re-eligible to contribute time at risk, as described.

A mixed linear model that included a random intercept and slope term for each cow was used to estimate LW on any given week relative to the week of lameness, taking into account the confounding effect of parity, breed, LW at calving, season, and calendar month. Our purpose was to estimate $\Delta \mathrm{LW}$ for the weeks before and after an identified lameness event. The timeframe of interest was the 8-wk period before and after an identified lameness event. We developed a derived variable of 18 levels termed LAMIDX: 8 levels for the $8 \mathrm{wk}$ before lameness week, 1 level for the week of lameness,
8 levels for the 8 wk after lameness week and 1 level for the weeks in which lameness was not observed. This allowed us to estimate the difference in $\mathrm{LW}$ at a given LAMIDX level compared with a specified reference level after adjusting for parity, breed, LW at calving, season, calendar month, and individual cow-level effects.

First-, second-, and third-order polynomials of weekly LW were used to represent the shape of the LW curve (Dohoo et al., 2009; p. 378). Breed, parity, LW at calving, season, and calendar month were entered into the model a priori as fixed effects. The LAMIDX variable was then entered and a Wald test performed to determine the significance of the regression coefficients for each level of LAMIDX. The levels of LAMIDX were then revised to include only those levels that were significant at an $\alpha$ level of 0.05 . The structure of the model was as follows:

$$
\begin{aligned}
y_{i p} & =\beta_{0}+\beta_{1} t_{i}+\beta_{2} t_{i}^{2}+\beta_{3} t_{i}^{3}+\text { parity }_{j}+\text { breed }_{k} \\
& +\beta_{4} \text { LWcalv }_{l}+\text { season }_{m}+\text { period }_{n}+\text { LAMIDX }_{o}[1] \\
& +\alpha_{0 p}+\alpha_{1 p} t_{i}+\alpha_{2 p} t_{i}^{2}+\varepsilon_{i p},
\end{aligned}
$$

where $y_{i p}$ is the $i$ th relative weekly (t) LW measured on $\operatorname{cow}_{p}, \beta_{0}$ is a regression coefficient for the intercept, and $\beta_{1}, \beta_{2}, \beta_{3}$, and $\beta_{4}$ are regression coefficients for the third-order polynomial terms to estimate weekly relative LW as a function of week in milk across all cows in the herd and LW at calving. The terms parity ${ }_{j}$,

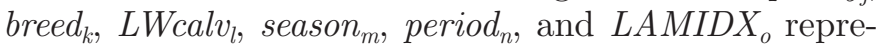
sent the fixed effects of parity, breed, LW at calving, season, and LAMIDX on $y_{i p}$, respectively. The random intercept $\left(\alpha_{0 p}\right)$, and random and slope terms $\left(\alpha_{1 p}\right.$ and $\alpha_{2 p}$ ) describe the deviation of cow $_{p}$ 's relative weekly LW from that of the rest of the herd; and $\varepsilon_{i p}$ represents the random residual error. Residuals errors were assumed to follow a first-order autoregressive correlation pattern for relative weekly LW measurements within each cow (Diggle, 2002). The order of the polynomial terms was based on the model's Akaike information criterion (AIC). Raw and normalized residuals were evaluated graphically against predicted values to test the assumption of homogeneity of variance of the error terms. The mixed model was fitted using the REML procedure within the nlme package (Pinheiro et al., 2008) in R (R Development Core Team, 2010).

\section{RESULTS}

Data from 828 lactations from 542 cows were used in these analyses. Twenty-two cows were excluded because of incomplete production records $(\mathrm{n}=8$ were culled and $\mathrm{n}=6$ died within the first $50 \mathrm{~d}$ postpartum) or 
Table 1. Incidence risk and incidence rate of lameness, stratified by diagnosis for the 2008 and 2009 milking seasons

\begin{tabular}{|c|c|c|c|c|c|}
\hline $\begin{array}{l}\text { Lameness } \\
\text { diagnosis }\end{array}$ & $\begin{array}{c}\text { Lame } \\
\text { (no.) }\end{array}$ & $\begin{array}{l}\text { Cows at } \\
\text { risk (no.) }\end{array}$ & $\begin{array}{l}\text { Cow-days at } \\
\text { risk (no.) }\end{array}$ & $\begin{array}{l}\text { Incidence } \\
\text { risk }^{1}\end{array}$ & $\begin{array}{l}\text { Incidence } \\
\text { rate }^{2}\end{array}$ \\
\hline Footrot & 33 & 828 & 199,346 & $3.9(2.8$ to 5.6$)$ & $0.02(0.01$ to 0.02$)$ \\
\hline White line disease & 54 & 828 & 184,646 & $6.5(4.9$ to 8.4$)$ & $0.03(0.02$ to 0.04$)$ \\
\hline Bruising and other causes & 18 & 828 & 209,846 & $2.2(1.3$ to 3.4$)$ & $0.01(0.00$ to 0.02$)$ \\
\hline Total & 105 & 828 & 222,446 & $13.0(11.0$ to 15.0$)$ & $0.05(0.04$ to 0.06$)$ \\
\hline
\end{tabular}

because they were observed to be lame in the first 50 $\mathrm{d}$ in milk $(\mathrm{n}=8)$. Table 1 show the total number of lameness cases detected and the total number of lameness lesions diagnosed in this herd over the 2 seasons. In total, 59 and 46 cases of lameness were detected in the 2008 and 2009 seasons, respectively. Over the 2 seasons, the lactation incidence risk of lameness was 13 cases per 100 cows (95\% CI: 10 to 15 cases per 100 cows; 105 of 828).

The effect of lameness on LW is shown in Table 2 . Negative values indicate weekly LW loss and positive values indicate weekly LW gain. Compared with the weeks in which lameness was not observed, lame cows experienced LW loss up to $3 \mathrm{wk}$ before a diagnosis of lameness was made. Lame cows lost the most LW in the week when lameness was detected $(12 \mathrm{~kg}, 95 \%$ CI: 10 to $14 \mathrm{~kg} ; P<0.01)$ and for 2 wk after $(11 \mathrm{~kg}, 95 \%$ CI: 9 to $13 \mathrm{~kg} ; 10 \mathrm{~kg}, 95 \% \mathrm{CI}: 9$ to $12 \mathrm{~kg}$, respectively). The total amount of LW loss arising from a lameness event was estimated to be $61 \mathrm{~kg}$ (95\% CI: 47 to $74 \mathrm{~kg})$.

\section{DISCUSSION}

Lameness is an important economic and animal welfare problem in pasture-fed dairy herds. Although some studies have investigated and quantified the effect of lameness on production loss, the effect on animal welfare is difficult to quantify. In this study, we investigated the effect of an observed lameness event using automatically recorded daily LW data collected in the 2008-2009 milking seasons. Our objective was to estimate the effect of observed lameness events on weekly LW change and to estimate the total amount of LW loss associated with these events. Our motivation for this was to provide a more quantitative estimate of lameness on productivity and animal wellbeing.

We identified LW loss up to 3 wk before a cow was detected as clinically lame by farm staff and presented for treatment (Table 2, Figure 1). The total amount of LW loss arising from a single lameness event after adjusting for the confounding effects of weeks in milk, parity, breed, LW at calving, calendar month, and season was estimated to be $61 \mathrm{~kg}$ ( $95 \%$ CI: 47 to 74 $\mathrm{kg})$. It is logical to assume that discomfort in a cow's leg or foot (depending on the severity of the causative lesion) will alter mobility, negatively affecting her ability to harvest forage (Maltz et al., 1997; Bach et al., 2007). Detecting lame cows is a challenging task for those managing dairy herds primarily because of a cow's natural instinct to mask any signs of pain or discomfort (O'Callaghan et al., 2003). In some cases, lame cows continue to produce milk and to breed, even in the absence of therapy (O'Callaghan et al., 2003). Better strategies need to be applied to detect lame cows early so that effective treatment can be initiated. Early diagnosis and appropriate treatment improves animal welfare, shortens recovery times, and reduces economic loss.

The increased amount of LW loss before a diagnosis of lameness could arise from a confounder that was associated with lameness later in lactation. For example, cows could have suffered an episode of a metabolic disorder such as ketosis or milk fever, causing increased LW loss and increasing the risk of becoming lame later in lactation (Green et al., 2002). In this case, the LW loss that occurred before lameness was diagnosed was due to a separate insult, and not by the identified lameness event. A more likely explanation is that cows were subclinically lame and were simply left undiagnosed (Whay, 2002) until their lesion become more obvious to farm workers as the severity of signs increased (Collick et al., 1989; Leach et al., 1997; Green et al., 2002)

The overall incidence risk of lameness for the 2 seasons over which this study was carried out was $13(95 \%$ CI: 11 to 15 ) cases per 100 cows at risk (Table 1). In the Manawatu region of New Zealand, Laven et al. (2008) evaluated lameness data from 2,800 dairy cows from 9 herds that were followed for a 4-mo period in the 2007-2008 milking seasons. During that time, 149 lameness events were recorded and the incidence risk was 17 (95\% CI: 13 to 19) cases per 100 cows at risk. Tranter and Morris (1991) monitored 831 cows from 3 herds in the same region between August 1989 and July 1990. In their study, 186 cows were observed as lame, 
Table 2. Estimated regression coefficients and their standard errors from a mixed-effects linear regression model of factors influencing liveweight in dairy cattle

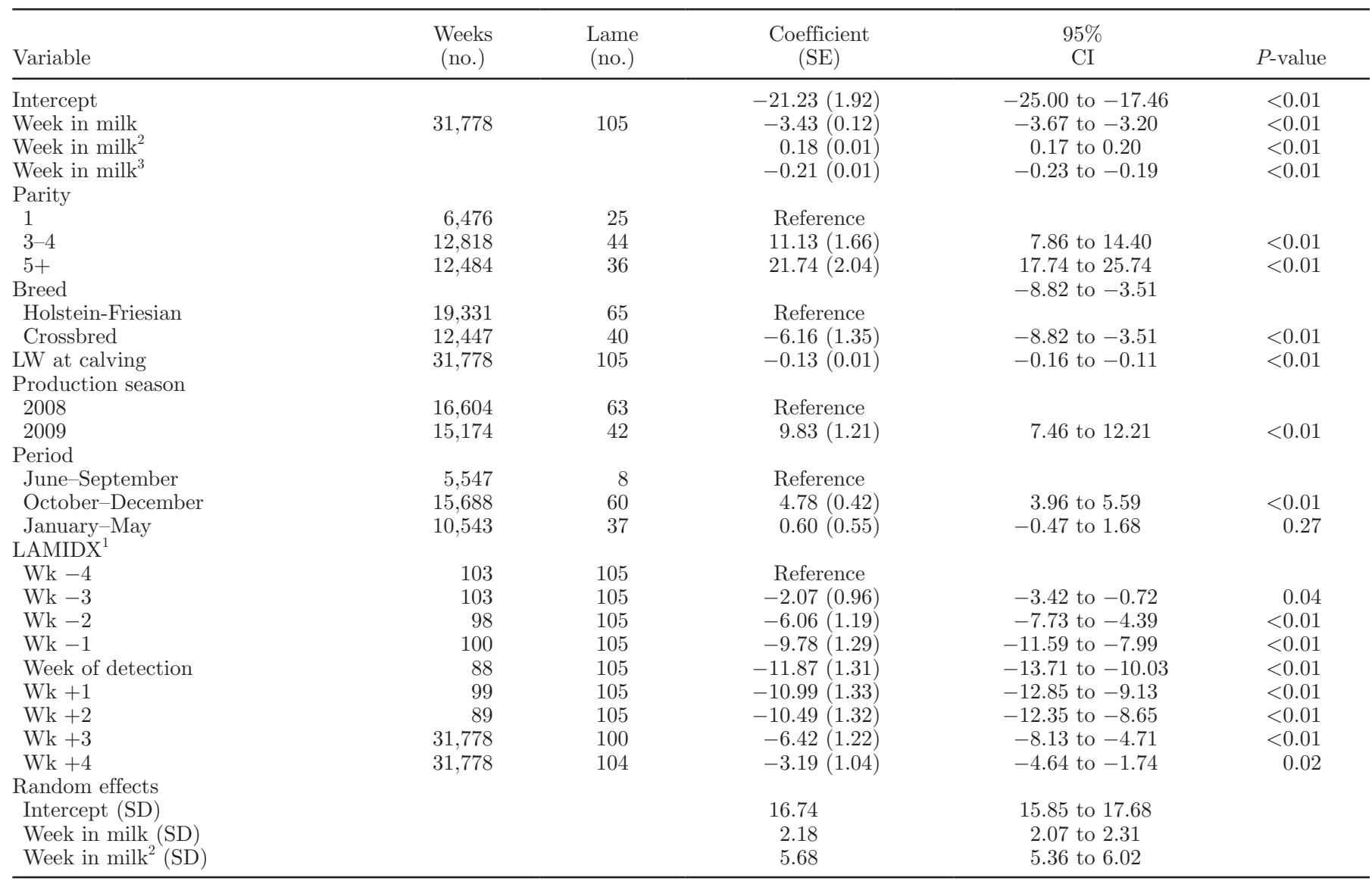

${ }^{1}$ LAMIDX $=$ a derived variable relating weekly liveweight to the week where lameness was observed.

producing an incidence risk of 16 (95\% CI: 14 to 18) cases per 100 cows at risk. The results of our study and those of Laven et al. (2008) and Tranter and Morris (1991) indicate that the incidence of lameness in this area of New Zealand has changed little over the past 18 yr. This can be attributed to consistent farming practice and a reasonably consistent level of surveillance to detect lameness cases within herds participating in observational epidemiological studies.

The most common cause of lameness in this study was white line disease ( $52 \%$ of all lame cows, 54 of $105)$, followed by footrot (31\%, 33 of 105) and bruising $(17 \%, 18$ of 105). Chesterton et al. (2008) evaluated lameness lesions from 4,488 dairy cows presented for veterinary examination in the Taranaki region from 1995 to 2007. In that period, white line disease was the most frequently reported lesion (42\%) followed by sole injury and bruising (29\%). Tranter and Morris (1991) reported similar findings. Although there is agreement in the reported incidence of lameness and partial disagreement in the lameness lesions reported between our study and the cited literature, these findings should be interpreted carefully because of an inherent level of misclassification bias that occurs because the design of our study relied on a herd manager's ability to assign a diagnosis to each identified lame cow.

In our study, selection bias may also have occurred due to differences in the diagnostic capability of individual farm staff. In the studies of Tranter and Morris (1991), Laven et al. (2008), and Chesterton et al. (2008), herd managers readily agreeing to take part in the respective studies may have been a form of selection bias. Tranter and Morris (1991), Laven et al. (2008), and Chesterton et al. (2008) may also have introduced medical surveillance bias. The herds used in these studies were those under the authors' veterinary care, and all cows observed as being lame (or suspected of being lame) were subject to veterinary examination for assessment and lesion diagnosis. Bias may have been introduced due to the higher than average veterinary encounters in the participating herds, resulting in improved disease surveillance. However, the Laven et al. (2008) and Tranter and Morris (1991) studies were descriptive and the authors did not directly examine 


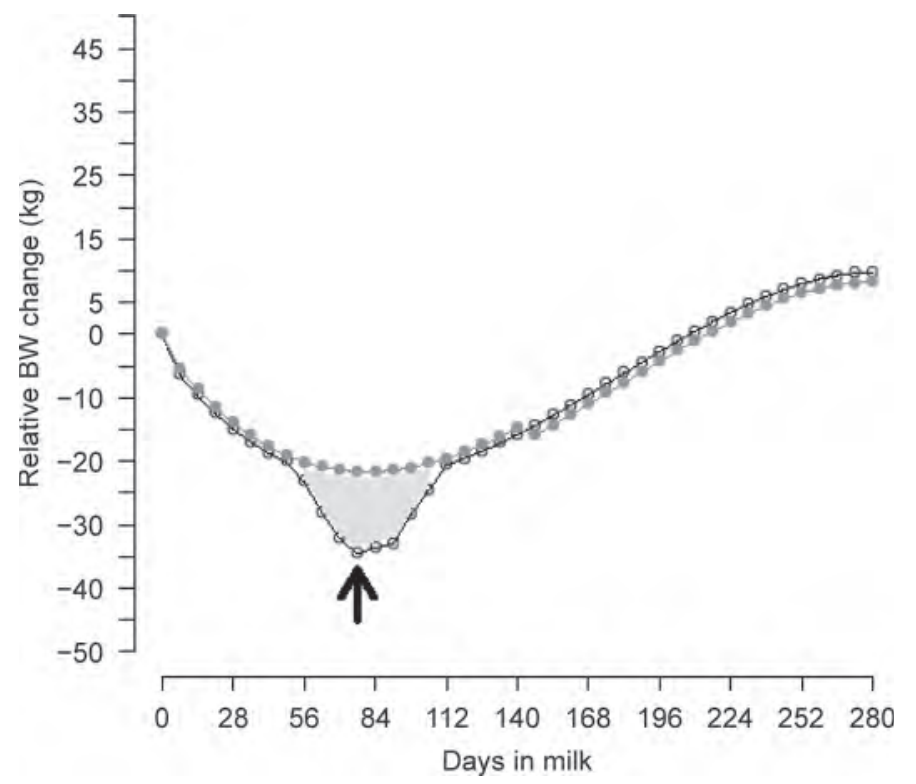

Figure 1. Line plot showing predicted weekly relative liveweight (LW) change of a nonlame (open circle) cow and a cow with a case of lameness in at 81 DIM (solid gray circle). The arrow indicates the time of diagnosis. The shaded gray area indicates the amount of LW loss of the lame cow (estimated from the random slopes and random intercepts model shown in Table 2 as the cumulative sum of LW estimates from -3 wk to 4 wk relative to time of lameness diagnosis).

the association between exposure variables and lameness. Nevertheless, if a measure of association were reported in those studies, it would have been biased away from the null, therefore strengthening the association between the exposure variable and lameness. Lack of denominator data in Chesterton et al. (2008) makes it difficult compare the overall incidence of lameness in that study with other studies.

One of the limitations of this study was that we did not distinguish between the type of foot lesion causing each lameness event. This was because the relatively small number of cases made it difficult to conduct a valid subgroup comparison. In addition, lameness detection was carried out by several farm staff over the course of the study. Variation in the diagnostic capability of farm staff represented a form of misclassification bias, presumed to be nondifferential. Overcoming this problem in future studies would be difficult. One approach might be to have farm staff take a digital photograph of each foot they examine (using, for example, a mobile phone) and then to have these photographs reviewed by an experienced veterinarian. Furthermore, the results presented here are only applicable to the study herd and are not likely to be generalizable to all herds. It is expected that different management practices and farm geographical location and topography would influence both the incidence and quantity of LW loss. However, the general principle, that lame cows do lose a significant amount of LW and do so before and after they are diagnosed as lame, is likely to be true in all pasture-fed dairy herds.

The difficulty in detecting lameness in individual animals in large herds (Chapinal et al., 2010) has led to increasing interest in alternative methods. Some of these focus on monitoring a cow's gait (Flower et al., 2006; Flower and Weary, 2006) or movement (Pastell et al., 2009) using image analysis techniques and accelerometers, respectively. Other studies focus on monitoring behavior such as the frequency and duration of resting (Ito et al., 2010) or feeding (González et al., 2008). A profitable area of future research might be to evaluate the sensitivity and specificity of lameness detection using one or more of these tools in combination with LW analyses similar to that described in this paper.

\section{CONCLUSIONS}

Observed lameness events were associated with a sharp decline in LW originating 3 wk before the week of lameness detection. The total amount of LW loss arising from a single lameness event was estimated to be $61 \mathrm{~kg}$ (95\% CI: 47 to $74 \mathrm{~kg})$. We propose that ongoing monitoring of LW in dairy herds could be a useful tool to assist herd managers in detecting lame cows. Real-time analysis of LW records should allow animals with acute and severe decreases in LW to be identified, signaling to a herd manager that these animals should be presented for examination. Identification of lame cows sooner rather than later means that appropriate therapy can be initiated. Shorter recovery times will have positive effects in terms of animal welfare.

\section{REFERENCES}

Alawneh, J. I., M. A. Stevenson, N. B. Williamson, N. Lopez-Villalobos, and T. Otley. 2011. Automatic recording of daily walkover liveweight of dairy cattle at pasture in the first 100 days in milk. J. Dairy Sci. 94:4431-4440.

Anonymous. 2010. National Dairy Statistics (2009-2010). Livestock Improvement Corporation, Hamilton, New Zealand.

Bach, A., M. Dinares, M. Devant, and X. Carre. 2007. Associations between lameness and production, feeding and milking attendance of Holstein cows milked with an automatic milking system. J. Dairy Res. 74:40-46.

Chapinal, N., A. M. de Passille, J. Rushen, and S. Wagner. 2010. Automated methods for detecting lameness and measuring analgesia in dairy cattle. J. Dairy Sci. 93:2007-2013.

Chesterton, R. N., K. E. Lawrence, and R. A. Laven. 2008. A descriptive analysis of the foot lesions identified during veterinary treatment for lameness on dairy farms in north Taranaki. N. Z. Vet. J. 56:130-138.

Collick, D. W., W. R. Ward, and H. Dobson. 1989. Associations between types of lameness and fertility. Vet. Rec. 125:103-106.

Diggle, P. J. 2002. Analysis of Longitudinal Data. Oxford University Press, Oxford, UK

Dohoo, I. R., W. Martin, A. H. Meek, and W. C. D. Sandals. 1983. Disease, production and culling in Holstein-Friesian cows. I. The data. Prev. Vet. Med. 1:321-334. 
Dohoo, I. R., W. Martin, and W. Stryhn. 2009. Page 378 in Veterinary Epidemiologic Research. AVC Inc., Charlottetown, Prince Edward Island, Canada.

Flower, F. C., D. J. Sanderson, and D. M. Weary. 2006. Effects of milking on dairy cow gait. J. Dairy Sci. 89:2084-2089.

Flower, F. C., and D. M. Weary. 2006. Effect of hoof pathologies on subjective assessments of dairy cow gait. J. Dairy Sci. 89:139-146.

Frost, A. R., C. P. Schofield, S. A. Beaulah, T. T. Mottram, J. A. Lines, and C. M. Wathes. 1997. A review of livestock monitoring and the need for integrated systems. Comput. Electron. Agric. $17: 139-159$.

González, L. A., B. J. Tolkamp, M. P. Coffey, A. Ferret, and I. Kyriazakis. 2008. Changes in feeding behavior as possible indicators for the automatic monitoring of health disorders in dairy cows. J. Dairy Sci. 91:1017-1028.

Green, L. E., V. J. Hedges, Y. H. Schukken, R. W. Blowey, and A. J. Packington. 2002. The impact of clinical lameness on the milk yield of dairy cows. J. Dairy Sci. 85:2250-2256.

Gröhn, Y. T., J. J. McDermott, Y. H. Schukken, J. A. Hertl, and S. W. Eicker. 1999. Analysis of correlated continuous repeated observations: Modelling the effect of ketosis on milk yield in dairy cows. Prev. Vet. Med. 39:137-153.

Holmes, C. W., I. M. Brookes, D. J. Garrick, D. D. S. Mackenzie, T. J. Parkinson, and G. F. Wilson. 2002. Milk Production from Pasture. Massey University, Palmerston North, New Zealand.

Ito, K., M. A. G. von Keyserlingk, S. J. LeBlanc, and D. M. Weary. 2010. Lying behavior as an indicator of lameness in dairy cows. J. Dairy Sci. 93:3553-3560.

Laven, R. A., K. E. Lawrence, J. F. Weston, K. R. Dowson, and K. J. Stafford. 2008. Assessment of the duration of the pain response associated with lameness in dairy cows, and the influence of treatment. N. Z. Vet. J. 56:210-217.

Leach, K. A., D. N. Logue, S. A. Kempson, J. E. Offer, H. E. Ternent, and J. M. Randall. 1997. Claw lesions in dairy cattle: Development of sole and white line haemorrhages during the first lactation. Vet. J. $154: 215-225$

Maltz, E., S. Devir, J. H. M. Metz, and H. Hogeveen. 1997. The body weight of the dairy cow. 1. Introductory study into body weight changes in dairy cows as a management aid. Livest. Prod. Sci. 48:175-186.

O'Callaghan, K. A., P. J. Cripps, D. Y. Downham, and R. D. Murray. 2003. Subjective and objective assessment of pain and discomfort due to lameness in dairy cattle. Anim. Welf. 12:605-610.

Onyiro, O. M., J. Offer, and S. Brotherstone. 2008. Risk factors and milk yield losses associated with lameness in Holstein-Friesian dairy cattle. Animal 2:1230-1237.

Pastell, M., J. Tiusanen, M. Hakojarvi, and L. Hanninen. 2009. A wireless accelerometer system with wavelet analysis for assessing lameness in cattle. Biosystems Eng. 104:545-551.

Pinheiro, J., D. Bates, S. DebRoy, D. Sarkar, and The R Core Team. 2008. nlme: Linear and Nonlinear Mixed Effects Models. R package version 3.1-88. R Foundation for Statistical Computing, Vienna, Austria.

R Development Core Team. 2010. R: A Language and Environment for Statistical Computing. R Foundation for Statistical Computing, Vienna, Austria.

Roche, J. R., N. C. Friggens, J. K. Kay, M. W. Fisher, K. J. Stafford, and D. P. Berry. 2009. Invited review: Body condition score and its association with dairy cow productivity, health, and welfare. J. Dairy Sci. 92:5769-5801.

Szklo, M., and F. J. Nieto. 2007. Epidemiology: Beyond the Basics, 2nd ed. Jones and Bartlett Publishers, Sudbury, MA.

Tranter, W. P., and R. S. Morris. 1991. A case study of lameness in three dairy herds. N. Z. Vet. J. 39:88-96.

Whay, H. 2002. Locomotion scoring and lameness detection in dairy cattle. In Pract. 24:444-449. 